\title{
Role of cranial ultrasound for diagnosis of intracranial abnormalities in newborns
}

\author{
Kumar N ${ }^{1}$, Singh MK ${ }^{2}$, Gupta AK ${ }^{3}$, Gill JPK ${ }^{4}$, Singh SK ${ }^{5}$, Gupta VK \\ ${ }^{1}$ Dr Neeraj Kumar, ${ }^{2}$ Dr Manoj Kumar Singh, ${ }^{3}$ Dr A K Gupta, ${ }^{4}$ Dr J P K Gill, ${ }^{5}$ Dr Shailendra Kumar Singh, ${ }^{6}$ Dr V K \\ Gupta. All are affiliated with S. N. Medical College Agra, India \& National JALMA Institute for Leprosy and Other \\ Microbial diseases Agra, India.
}

Address for correspondence: Dr Neeraj Kumar, Email: neerajyadu@rediffmail.com

\begin{abstract}
Aim: To evaluate the role of cranial ultrasound in neonates and infants in diagnosis of various intracranial abnormalities. Method: A real time cranial ultrasound was performed on 98 neonates and 33 infants of 1 month to 1 year of age group including the all preterms and symptomatic term neonates and infants during the study period. Result: Sonography results in symptomatic premature neonates showed Germinal Matrix haemorrhage in $67.56 \%$, hydrocephalus in $37.83 \%$ and peri-ventricular leukomalacia in $24.31 \%$, while in asymptomatic premature newborn, sonography showed germinal matrix haemorrhage/hydrocephalus in $27.5 \%$ and normal scan in rest of them. In symptomatic full term neonates, sonography showed hydrocephalus in $76.19 \%$, germinal matrix hemorrhage in $19.04 \%$, cystic encephalomalacia in $14.28 \%$, porencephaly in $9.52 \%$, hydrancephaly in $4.76 \%$ and normal scan in $14.28 \%$. Sonographic scan in symptomatic infants of more than 1 month of age showed - echogenic sulci in $39.39 \%$ cases, hydrocephalus in $33.33 \%$, cerebritis in $15.15 \%$, cerebral abscess in $6.06 \%$, mass lesions in $3.03 \%$ and normal scan in $24.24 \%$ cases. Conclusion: Because of being safe, nonionising and easily available, cranial ultrasound can be used as a primary imaging modality to detect intracerebral lesions in neonates and infants.
\end{abstract}

KeyWord: Sonography, Germinal Matrix haemorrhage, neonates and infants.

\section{Introduction}

The most crucial period for a child, one that has deepest impact on his life expectancy is the neonatal period to first year of life. Infant and neonatal mortality rate is thus the most important indicator of health status of a community. Infections (36\%), preterm birth $(28 \%)$ and birth asphyxia (23\%) account for $87 \%$ of neonatal deaths worldwide. There is some variation between countries depending on their care configuration $[1,2,3]$. The common causes of neonatal deaths in India include infections, birth asphyxia, and prematurity which contribute to $32.8 \%, 22.3 \%$, and $16.8 \%$ of the total neonatal deaths, respectively $[4,5]$.

Complications of premature birth include bleeding in the brain and/or in the ventricles (intraventricular haemorrhage or IVH) and Periventricular leukomalacia (PVL) [6]. Most cases of IVH can be detected by

Manuscript received: $22^{\text {nd }}$ January 2016

Reviewed: $2^{\text {nd }} \mathrm{Feb} 2016$

Author Corrected; $18^{\text {th }} \mathrm{Feb} 2016$

Accepted for Publication: $29^{\text {th }}$ Feb 2016 cranial ultrasound in first week after delivery. Both IVH and PVL increases a baby's risk of developing disabilities that may range from mild learning or gross motor delays to cerebral palsy or mental retardation $[7,8]$. There is a wide spectrum of congenital abnormality affecting the intracranial compartment. These are broadly classified into disorder of neural tube closure, diverticulation, cleavage, sulcation, neuronal migration and posterior fossa developmental defects. Dewbury et al in 1980 first reported the use of anterior fontanelle as a bone free window through which brain can be imagined. Since then this technique has become widely accepted and is regarded as a primary imaging method for the neonatal brain [9].

Despite the advances in computed tomography (CT) and magnetic resonance imaging (MRI), ultrasound (US) is the most commonly used modality for examining the newborn brain. Ultrasound is still the only modality able to image the brain at the bedside, 
which can be vitally important in the case of the critically ill infant. CT and MRI require sedation, transportation to machine having the hypothermic environment and prolonged time for optimal imaging. Also of benefit to the newborn is that ultrasound is easily reproducible and does not produce any ionizing radiation. Of the three aforementioned modalities, however, ultrasound is by far the most operatordependent [10].

Cranial ultrasound uses reflected sound wave to produce image of brain and the inner fluid chambers (ventricles) through which the cerebrospinal fluid (CSF) flows [11]. This investigation is most commonly done on neonates to evaluate complication of premature birth. The most common abnormalities of the neonatal brain requiring confirmation or exclusion by imaging are hydrocephalus, intracranial haemorrhage and/or related hypoxic-ischemic damage. Less frequent indications for scanning are suspected intracranial sepsis and tumour $[12,13,14]$.

Technical advances in ultrasound examination have made this a highly sensitive means to detect and guide treatment for pediatric cranial pathologies [15].

Non-invasive and rapid evaluation of brain in the neonatal and infants with reproducible result is now feasible with real time high resolution cranial sonography through the anterior fontanelle. It has key role in the initial evaluation and monitoring of ventricular dilatation in the newborns [16,17]. Ventricular size, intracranial haemorrhage, abnormalities of ventricular system, subdural effusion and cystic lesion are recognized by usual sonographic criteria [16]. Mastoid fontanelle imaging is particularly useful in detecting haemorrhage involving the brainstem, cerebellum and subarachnoid cisterns.

Cranial ultrasonography offers an excellent anatomic imaging of the brain when evaluating for congenital anomalies and plays an important role in the diagnosis of inflammatory processes [18].

\section{Material and Method}

98 neonates (among which 77 were preterm and 21 were full term) and 33 infants of age more than one month were included in the study who were delivered in the obstetric department of S.N. Medical College, Agra and those who were admitted in Department of Paediatrics of the S.N. Medical College, Agra.

Informed consent was taken from the parents before the commencement of the study. After taking the ethical clearance from the ethical committee of the college, all the preterm neonates, term neonate and infants who presented with clinical features suggestive of CNS involvement (hypotonia, convulsions, letharginess, sudden pallor, refusal to take feeds, bulging fontanelle, decebrate rigidity) were enrolled in the study.

All the preterm were screened with cranial ultrasound irrespective of the clinical status and term neonates and infants presenting with CNS symptoms were included in the study. Premature babies were examined as early as possible and scanning was repeated on the $7^{\text {th }}$ and $21^{\text {st }}$ days of the first scan or on development /deterioration of symptoms. The examination was done on MEDISON - SA-8000 ULTRASOUND MACHINE. By 3-7.5 MHz sector probe. Anterior and posterior fontanelle were used as windows for ultrasound scanning. Recording was done on gray imaging film. Coronal and sagittal scans were obtained using multiple angulated views.

The cranial ultrasound were evaluated as following-

1. Size and shape of ventricles.

2. Presence or absence of intraventricular echo

3. Periventricular area

4. Lateral ventricle to hemisphere ratio

5. Falx cerebri and midline structures and shift thereof

6. Status of the choroid plexus

7. Echogenecity of cerebral parenchyma

8. Sylvian fissure, cingulated and hippocampal gyri

9. Any abnormal hyper or hypoechoic area

10. Any mass lesion.

\section{Results}

In our study 131 cases were included out of them 77 were preterm, out of which 37 (48.06\%) were symptomatic and 40 (51.94\%) were asymptomatic. 21 cases were full term neonates and 33 were infants with age more than 1 month.

In premature neonates, hypotonia $(67.5 \%)$ and sudden pallor $(59.45 \%)$ were the predominant symptoms while the other symptoms were refusal of feed $(40.5 \%)$, bulging fontanelle $(35.1 \%)$, convulsions $(51.3 \%)$, decerebrate rigidity $(21.6 \%)$. In full term neonates, bulging fontanelle $(76.1 \%)$ and hypotonia $(61.9 \%)$ were predominant symptoms while in the infant fever $(75.7 \%)$ and convulsions (42.4\%) were main symptoms. 
Table 1: Symptom wise distribution of the cases

\begin{tabular}{|c|l|l|l|l|}
\hline S. No & Symptom & $\begin{array}{l}\text { Premature } \\
\text { Newborns } \\
(\mathbf{n}=\mathbf{3 7})\end{array}$ & $\begin{array}{l}\text { Term Newborns } \\
(\mathbf{n}=\mathbf{2 1})\end{array}$ & $\begin{array}{l}\text { Infants } \\
(\mathbf{n}=\mathbf{3 3})\end{array}$ \\
\hline 1 & Hypotonia & $25(67.56 \%)$ & $13(61.90 \%)$ & $6(18.18 \%)$ \\
\hline 2 & Sudden Pallor & $22(59.45 \%)$ & $8(38.09 \%)$ & 0 \\
\hline 3 & Refusal to feed & $15(40.54 \%)$ & 0 & $11(33.33 \%)$ \\
\hline 4 & Bulging Fontanelle & $13(35.13 \%)$ & $16(76.19 \%)$ & 0 \\
\hline 5 & Convulsions & $19(51.35 \%)$ & $5(23.8 \%)$ & $14(42.42 \%)$ \\
\hline 6 & Decerebrate Rigidity & $8(21.62 \%)$ & 0 & 0 \\
\hline 7 & Tachycardia & $19(51.35 \%)$ & 0 & 0 \\
\hline 8 & Tachypnoea & $17(45.94 \%)$ & 0 & 0 \\
\hline 9 & Neurological Deficit & 0 & $11(52.38 \%)$ & $8(24.42 \%)$ \\
\hline 10 & Fever & 0 & 0 & $25(75.75 \%)$ \\
\hline
\end{tabular}

Table 2: Cranial USG abnormalities in premature babies

\begin{tabular}{|c|l|l|l|}
\hline S. No. & Sonographic Abnormality & $\begin{array}{l}\text { No. of Symptomatic } \\
\text { Premature babies }\end{array}$ & $\begin{array}{l}\text { No. of Asymptomatic } \\
\text { Premature babies }\end{array}$ \\
\hline 1 & $\begin{array}{l}\text { Germinal Matrix Haemorrhage \&/or } \\
\text { Hydrocephalus }\end{array}$ & $28(75.67 \%)$ & $11(27.5 \%)$ \\
\hline 2 & Periventricula Leukomalacia & $9(24.31 \%)$ & 0 \\
\hline 3 & Normal Sonogram & 0 & $29(72.5 \%)$ \\
\hline
\end{tabular}

Figure.1: Sonographic abnormalities distribution in full term neonates

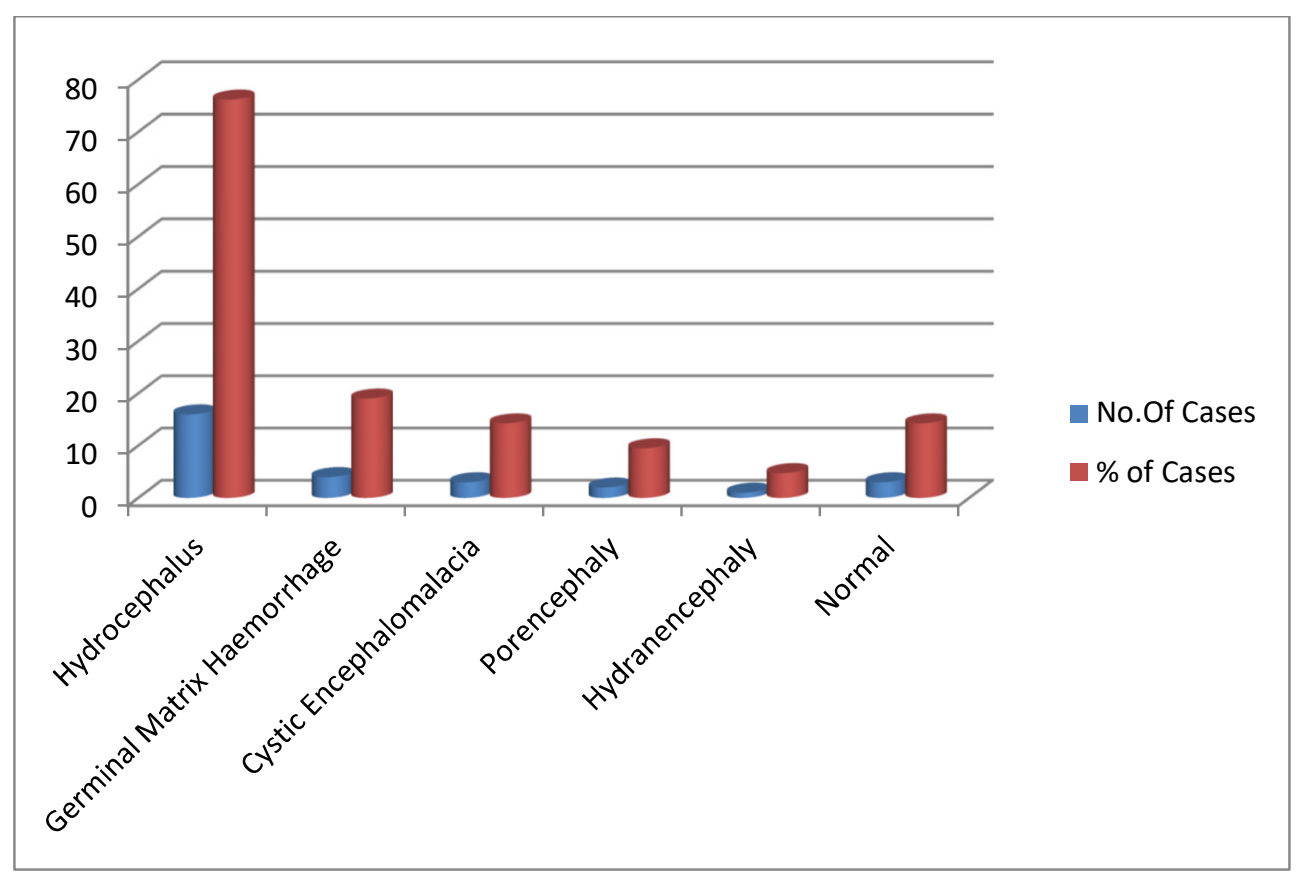


Figure-2: Sonographic abnormalities distribution in infants.

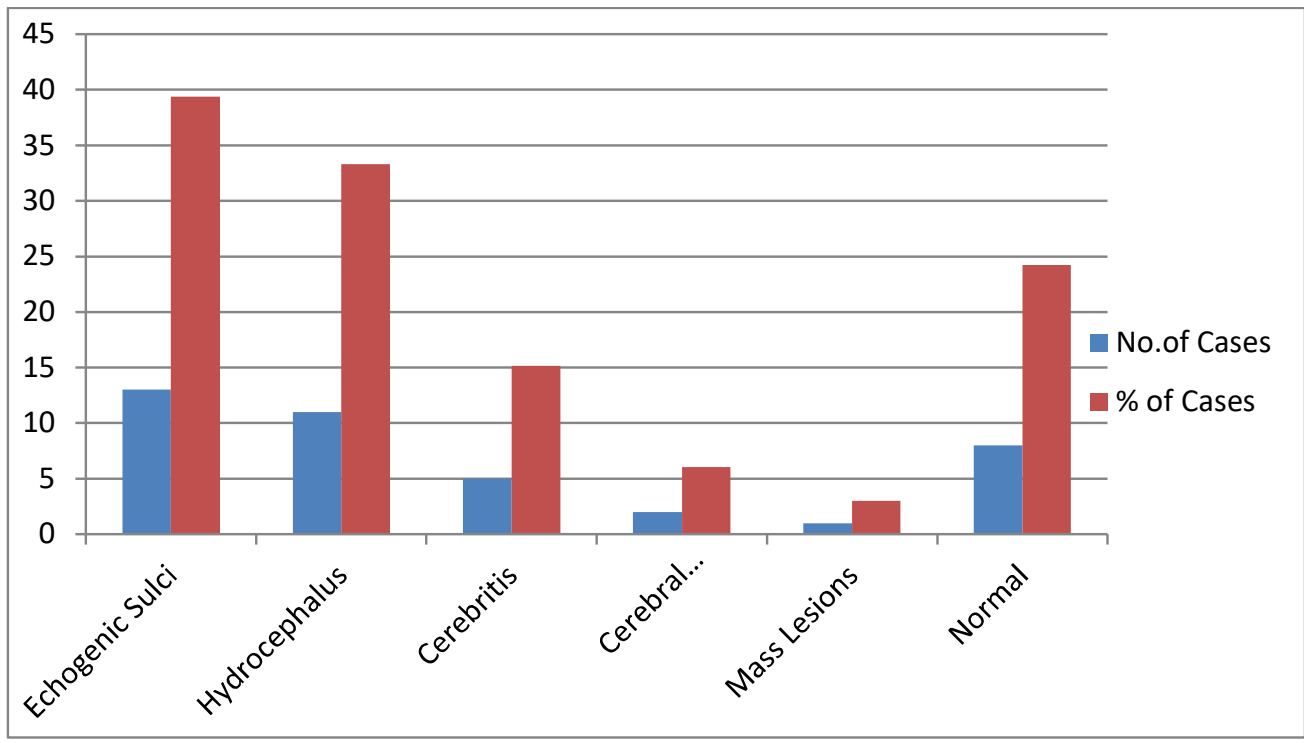

In symptomatic premature neonates, sonography showed Germinal Matrix haemorrhage in $67.56 \%$, hydrocephalus in $37.83 \%$ and peri-ventricular leukomalacia in $24.31 \%$; while in asymptomatic premature newborn, sonography showed germinal matrix haemorrhage/hydrocephalus in $27.5 \%$ and normal scan in rest of them.

In symptomatic full term neonates, hydrocephalus $(76.19 \%)$ was the predominant finding on sonography while germinal matrix hemorrhage (19.04\%), cystic encephalomalacia (14.28\%), porencephaly $(9.52 \%)$, hydrancephaly $(4.76 \%)$ was noticed and $14.28 \%$ were normal on the scanning.

Sonographic scan in symptomatic infants of more than 1 month of age showed - echogenic sulci in $39.39 \%$ cases, hydrocephalus in $33.33 \%$ caes, cerebritis in $15.15 \%$ cases, cerebral abscess in $6.06 \%$, mass lesions in $3.03 \%$ cases and normal scan in $24.24 \%$ cases.

\section{Discussion}

Transfontanelle cranial sonography is an important investigation for evaluation of the neurological status of neonates and infants, whether symptomatic or asymptomatic.

The commonest symptom among the premature newborns is hypotonia which is similar to study done by Mercury et al. They found abnormal tone in 25 cases out of 43 cases of abnormal neurological pattern during the study on cranial sonography [19].

The commonest finding in premature babies was germinal matrix haemorrhage followed by hydrocephalus and periventricular leukomalacia which is consistent with the results of the study done by Sims ME et al who found intracranial haemorrhage in 150 cases out of 170 cases [20].

The incidence of germinal matrix haemorrhage decreases with increasing gestational age which is

similar to results in the study done by Perry et al [21]. Hydrocephalus was a common accompaniment of intraventricular haemorrhage in our study which is similar with the study done by Ment LR et al [22]. $27.5 \%$ of premature newborns had germinal matrix haemorrhage without manifesting any sign there of ( this means that the use of clinical criteria to screen the babies would lead to under diagnosis).

In full term neonates, hydrocephalus was the commonest sonographic finding followed by germinal matrix haemorrhage. The results are consistent with Edwards et al who found that ventricular enlargement is the common finding in $37.5 \%$ cases [23].

The two most common sonographic finding in symptomatic infants were echogenic sulci and hydrocephalus in our study. The detailed study could not be available because the incidence of infections is not known. 


\section{Conclusion}

Germinal matrix haemorrhage is the commonest finding on cranial sonography in premature newborns while hydrocephalus is the commonest in full term newborns. Hypotonia is the most common manifestation of germinal matrix haemorrhage. A large number of premature infants with intraventricular haemorrhage are asymptomatic. These facts infer that all premature newborns should be screened by cranial sonography.

Because of being safe, non-ionising, and easily available, cranial ultrasound can be used as a primary imaging modality to detect intracerebral lesions in all premature neonates and symptomatic term newborns and infants with open anterior fontanels.

\section{Source of Support: Nil \\ Conflict of Interest: None \\ Permission of IRB: Yes}

\section{References}

1. Högberg U. The World Health Report 2005: "make every mother and child count" - including Africans. Scand J Public Health. 2005;33(6):409-11.

2. Lawn JE, Cousens S, Zupan J; Lancet Neonatal Survival Steering Team. 4 million neonatal deaths: when? Where? Why? Lancet. 2005 Mar 511;365(9462):891-900.

3. Lawn JE, Cousens SN, Wilczynska K. Estimating the causes of four million neonatal deaths in the year 2000 : statistical annex. In : The world health report 2005. Geneva: WHO; 2005

4. ICMR Young Infant Study Group. Age profile of neonatal deaths. Indian Pediatr. 2008 Dec;45(12):991-4.

5. T. Bang, V. K. Paul, H. M. Reddy, and S. B. Baitule, Why do neonates die in rural Gadchiroli, India? (Part I): primary causes of death assigned by neonatologist based on prospectively observed records, Journal of Perinatology, vol. 25, supplement 1, pp. S29-S34, 2005. View at Publisher View at Google Scholar

6. Adams C, Johnston WP, Nevin NC. Family study of congenital hydrocephalus. Dev Med Child Neurol. 1982 Aug;24(4):493-8.

7. Armstrong DL, Sauls CD, Goddard-Finegold J. Neuropathologic findings in short-term survivors of intraventricular hemorrhage. Am J Dis Child. 1987 Jun;141(6):617-21.
8. Ambrosino MM, Hernanz-Schulman M, Genieser NB, Wisoff J, Epstein F. Brain tumors in infants less than a year of age. Pediatr Radiol. 1988;19(1):6-8.

9. Dewbury KC, Aluwihare AP. The anterior fontanelle as an ultrasound window for study of the brain: a preliminary report. Br J Radiol. 1980 Feb;53(626):81-4.

10. Sonography of the neonatal brain" Journal of Diagnostic Medical Sonography Volume 25, Issue 6, November 2009, Pages 331-348 DOI : 10.1177 / 8756479309347801 .

11. Levene MI. Measurement of the growth of the lateral ventricles in preterm infants with real-time ultrasound. Arch Dis Child. 1981 Dec;56(12):900-4.

12. Rumack CM, Drose JA. Neonatal and infant brain imaging. In: Rumack CM, Wilson SR, Charboneau JW (eds). Diagnostic Ultrasound. Vol 2. 4th ed. Philadelphia, PA: Elsevier; 2011:1558-1636.

13. Siegel MJ. Brain. In: Siegel MJ (ed). Pediatric Sonography. 4th ed. Philadelphia, PA: Lippincott Williams \& Wilkins; 2011:43-117. 5. Slovis TL, Bulas DI, Nelson MD. Neonatal brain imaging.

14. Slovis TL, Coley BD, Bulas DI, et al (eds). Caffey's Pediatric Diagnostic Imaging. Vol 1. Philadelphia, PA: Elsevier; 2008:398-429.

15. Kristin Fickenscher, Zachary Bailey, Megan Saettele, Amy Dahl and Lisa Lowe (2012). Pediatric Cranial Ultrasound: Techniques, Variants and Pitfalls, Neuroimaging - Methods, Prof. Peter Bright (Ed.), ISBN:978-953-51-0097-3.

16. BANKER BQ, LARROCHE JC. Periventricular leukomalacia of infancy. A form of neonatal anoxic encephalopathy. Arch Neurol. 1962 Nov;7:386-410.

17. Barkovich AJ, Kjos BO, Norman D, Edwards MS. Revised classification of posterior fossa cysts and cystlike malformations based on the results of multiplanar MR imaging. AJR Am J Roentgenol. 1989 Dec;153(6):1289-300.

18. Barson AJ. Spina bifida: the significance of the level and extent of the defect to the morphogenesis. Dev Med Child Neurol. 1970 Apr;12(2):129-44.

19. Mercuri E, Dubowitz L, Brown SP, Cowan F: incidence of cranial ultrasound abnormalities in 
neonates and association with post natal factors and neurological status. Arch Dis Child Fetal Neonatal Ed 1998; 79(3):F185-9.

20. Sims ME, Turkel SB, Halterman G, Paul RH. Brain injury and intrauterine death. Am $J$ Obstet Gynecol. 1985 Mar 15;151(6):721-3.

21. Perry RN, Bowman ED, Murton LJ, Roy RN, de Crespigny L. Cranial ultrasound screening of preterm and term neonates. Aust Paediatr J. 1987 Feb;23(1):313.

\section{How to cite this article?}

Sunilkumar MN, Gayathrivarma N, Parvathy V.K, Assessment of renal parenchymal changes using isotope renography for genitourinary indications in pediatric age group-a study of 47 cases:Int J Pediatr Res 2016;3(4):240245.doi:10.17511/ijpr.2016.i04.06.
22. Ment LR, Duncan CC, Scott DT, Ehrenkranz RA. Posthemorrhagic hydrocephalus. Low incidence in very low birth weight neonates with intraventricular hemorrhage. J Neurosurg. 1984 Feb;60(2):343-7.

23. Edwards MK, Brown DL, Muller J, Grossman CB, Chua GT. Cribside neurosonography: real-time sonography for intracranial investigation of the neonate. AJR Am J Roentgenol. 1981 Feb;136(2):271-5. 